\title{
ADMINISTRATION OF MENTAL HEALTH SERVICES BY MEDICAID AGENCIES
}

James Verdier, Allison Barrett, and Sarah Davis

\section{SAMHSAVMMS Conference on MJedjcaljd and Mental Health Services}

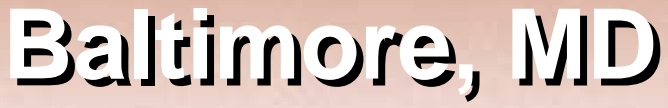

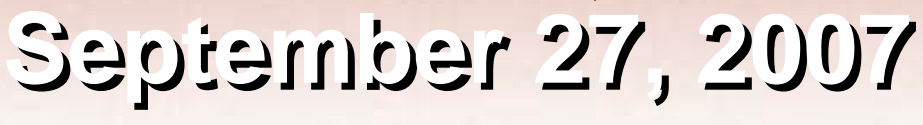




\section{Introduction}

- Presentation is based on results from a SAMHSAfunded Mathematica telephone survey of Medicaid directors or designees in $\mathbf{5 0}$ states and DC in 20052006

- Full report is on the SAMHSA web site

, Survey asked questions about the Medicaid agency's role in administering Medicald-funded mental health (MH) services, and the degree of shared responsibility with the state $\mathrm{MH} H$ agency

- Five major areas of the survey were organizational structure, collaboration, funding, covered services and providers, and data sharing and reports 


\section{Overview of Presentation}

- Background and context

- Descriptive summary of survey results

- Analysis of four state types

- States with higher and lower levels of Medicaid and $\mathrm{MH}$ agency collaboration

- States with higher and lower Medicaid agency authority over Medicaid MH services

- Conclusions

- Importance of Medjicajid-MH collaboration

- Riole of working groups

- Riole of county/local lyll authorities

- Impact of state government reorganizations 


\section{Background}

- Medicaid spending for MH services accounted for 26 percent of total $\mathrm{MH}$ expenditures by all public and private payers combined in 2003 , up from 21 percent in 1993 and 14 percent in 1971 (Mark et al. 2007, Frank and Glied 2006)

- Other state and local MH spending dropped from 30 percent in 1971 to 27 percent in 1993 and 21 percent in 2003

- Medicaid now funds more than half of all MH services administered by the states, and could account for two-thirds of such spending by 2017 (Buck 2003)

- 10 percent of all IJedjicajd dollars were spent on $\mathrm{MJ} \mathrm{H}$ services in 2003 (Nilark et al. 2007) 


\section{Background (Cont.)}

- State MH services have shifted from institutional care (funded primarily by $\mathrm{MH}$ agencies) to community care (funded more by Medicaid) (White and Draper 2004)

- Number of inpatient psychiatric beds in state and county hospitals fell by more than half between 1970 and 1980 (Frank and Glied 2006)

- States have sought to maximize Medicaijd funding for state MH services (White and Draper 2004)

- Substifutes 50-7.6\% federal matching payments for $100 \%$ state dollars

- Shifits responsibility from MlH agencies to Jjedicaijd agencies 


\section{Background (Cont.)}

- Because Medicaid is a joint state-federal program, key aspects of the program affecting MH services can vary substantially from state to state

- Federal law requires state Medicaid agencies to retain ultimate authority over all Medicaid services, but they can delegate day-to-day responsibility to the state MH agency to, e.g, certify and enroll providers, define covered services, set rates, and collect and report data

- States can choose to cover additional MH services under Mledicaid, such as:

- Inpatient psychiatric services for children/elderly

- Outpatient rehabilitative services

- Clinjeal services provided by a psychifatrist, psychologjist, or socjal worker 


\section{Medicaid MH Services}

- The following services were defined as Medicaid MH services in the majority of states:

- Outpatient services provided by psychiatric or designated mental health providers (51)

- Outpatient services provided at a community mental health center (49)

- Outpatient mental health services provided by a general or family physicjan (31)

- The most common other services defined as Medicaid MH services Were targeted case management and EPSDT MJH services for childdren 


\section{MH Agency Rate-Setting Authority}

- The MH agency set some rates for Medicaid MH services in $\mathbf{2 5}$ states

- Most common Medicaid services for which MH agencies had rate-setting authority were:

- Residential treatment (17 states)

- Psychiatric socjal workers, targeted case management, and psychosocjal rehabilitation (16 states each)

- Partial day treatment (15 states) 


\section{Managed Care}

- In 34 states, some MH services or populations were carved out of Medicaid managed care

- In 25 states, the state contracts with a behavioral health organization (BHO) or an administrative services organization (ASO) to deliver Medicaid MH services

- Unfortunately, the data we collected generally do not enable us to tell how services "carved out" of Whedjcajd managed care were handled, or whether Medjicajd and Mlil agencjes collaborated on managed care program design or implementation issues 


\section{Medicaid Funding for MH Services}

- MH services were a separate line item in the Medicaid budget in 23 states

- Some Medicaid MH services were funded by the MH agency in 32 states

, Medicaid MH services were funded in part by county governments in 22 states

- There was a dedjicated fundling stream for Medjcaid IJ services separate from the state general fund in 9 staties 


\section{Organizational Placement of Medicaid and MH Agencies and Opportunities for Collaboration}

- Medicaid and MH were in the same umbrella agency in 28 states in 2005-2006, and different agencies in 22 states and DC

- Growing role of Medicaid in funding MH services increases importance of collaboration with $\mathrm{MH}$ agencies on policy and implementation issues

- In general, collaboration was more common when both Medicaid and MH were in same umbrella agency (Exhibit 1) 


\section{Exhibit 1 \\ Organizational Structure and Collaboration Between Medicaid and Mental Health Agencies}

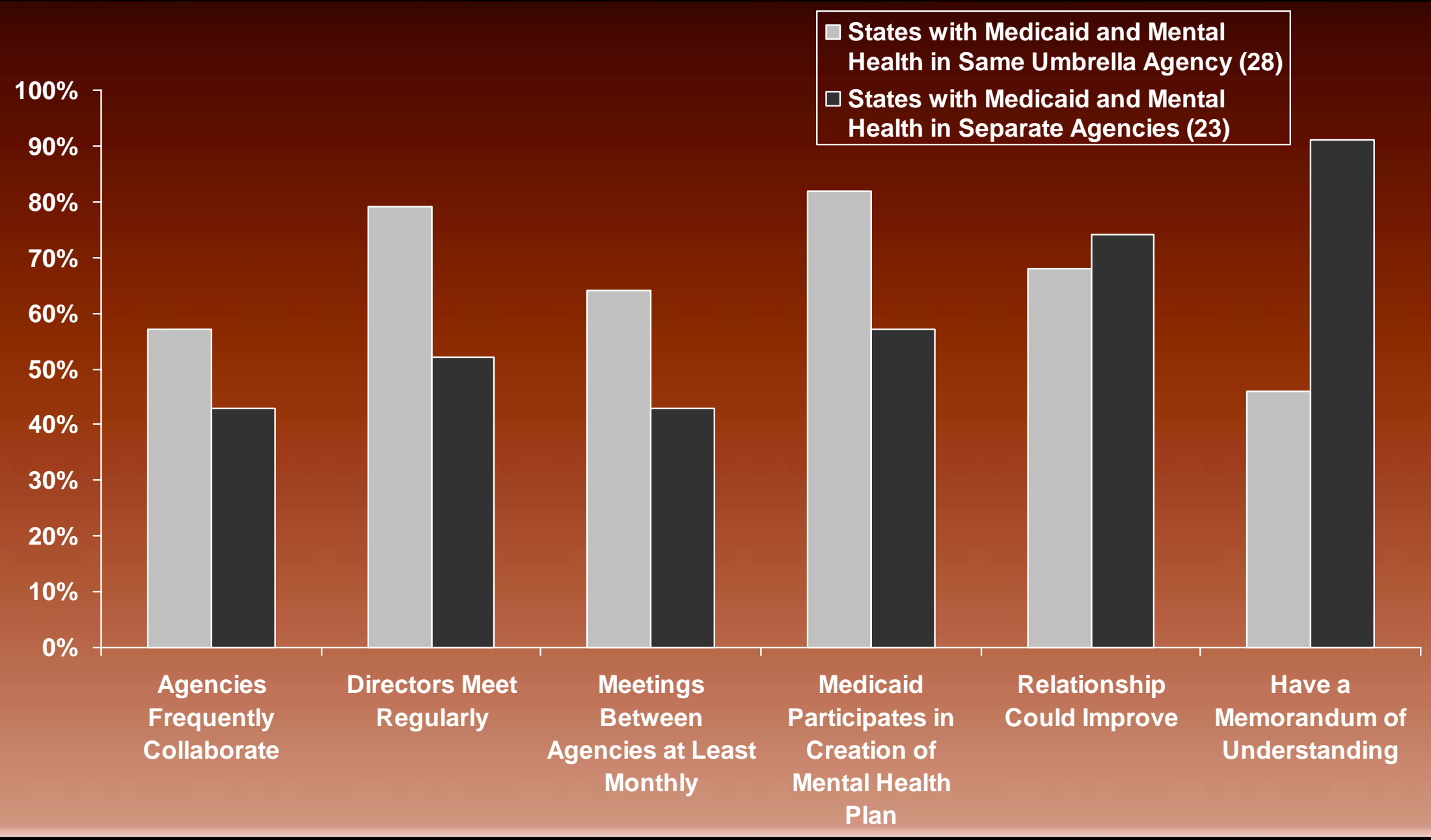




\section{Reports and Data Sharing}

- 40 states reported that the Medicaid agency produces formal reports that contain discrete data on $\mathrm{MH}$ service utilization or expenditures

- 27 states reported that the MH agency also produced such reports

- 8 reported that only the MH agency produced them

- Reports most commonly contained number of beneficjaries using MH services (32 states), utilization (30 states), cost by service (29 states), and cost per beneficjary (26 states)

- In 39 states, LJedjicajol clajms data (from MJMJIS) were macle available to lis] agency for analysis 


\section{Integrated Medicaid and MH Data}

- In 16 states, the Medicaid agency has linked clientlevel data with the MH agency

- In 7 states, Medicaid agency has linked such data with the state Substance Abuse agency

, Medicaid data linking with other state agencies

- Social Services (111 states)

- Children and Family Services (10)

- Corrections (7)

- Health (7)

- Juvenile Justice (4) 
Umbrella Agencies, Rate-Setting Authority, and Data Sharing

- Data sharing appears to be comparable in states with Medicaid and MH in same umbrella agency and in separate agencies (Exhibit 2)

- When MH agency has authority to set some Medicaid rates, however, $\mathrm{MH}$ agency has greater access to Medjcaid data and produces more reports on Medjcaijd MH services (Exhibit 3) 


\section{Exhibit 2 \\ Umbrella Agencies and Data Sharing}

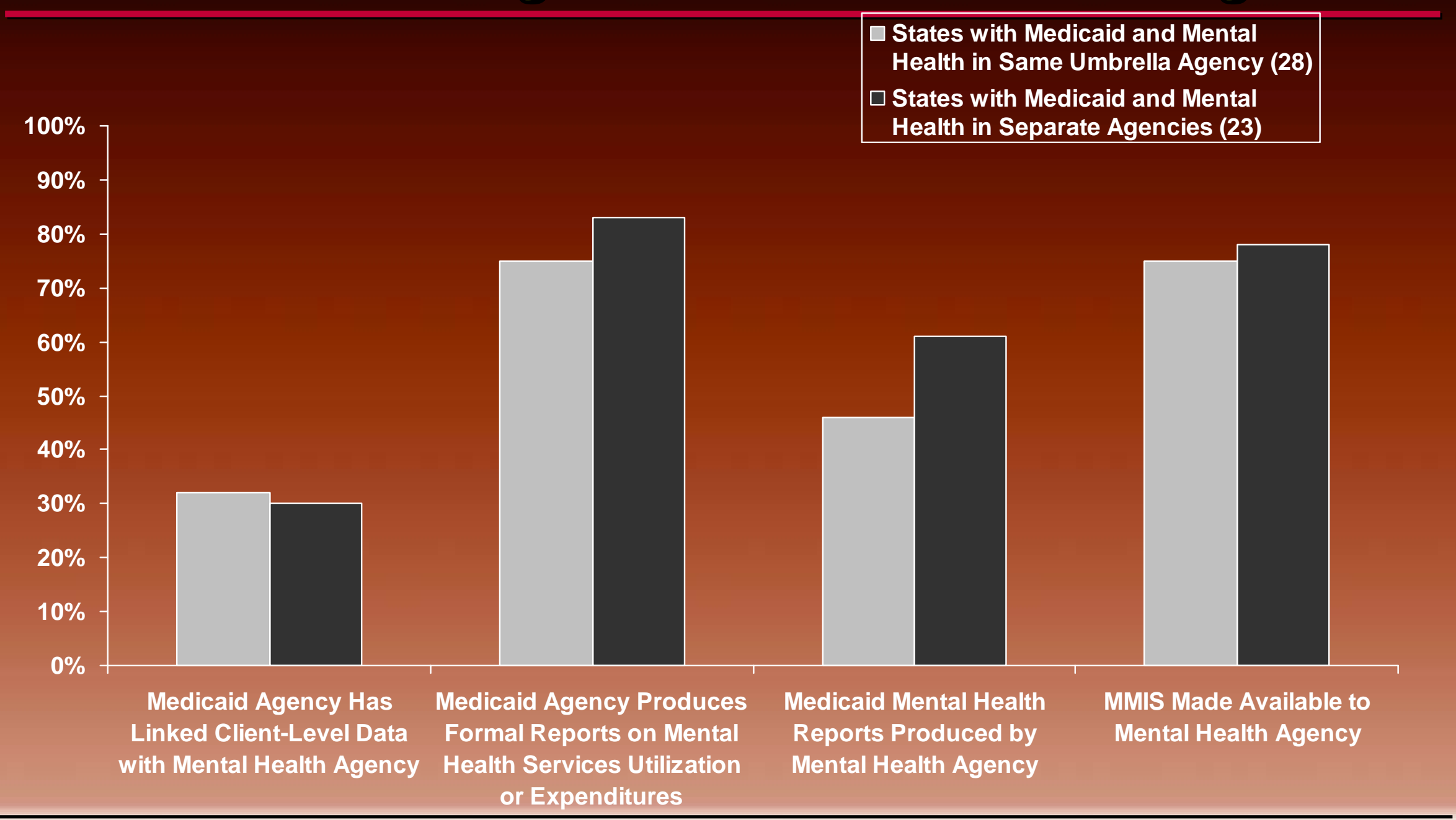




\section{Exhibit 3}

\section{Rate-Setting Authority, Mental Health Services Reports, and Data Sharing}

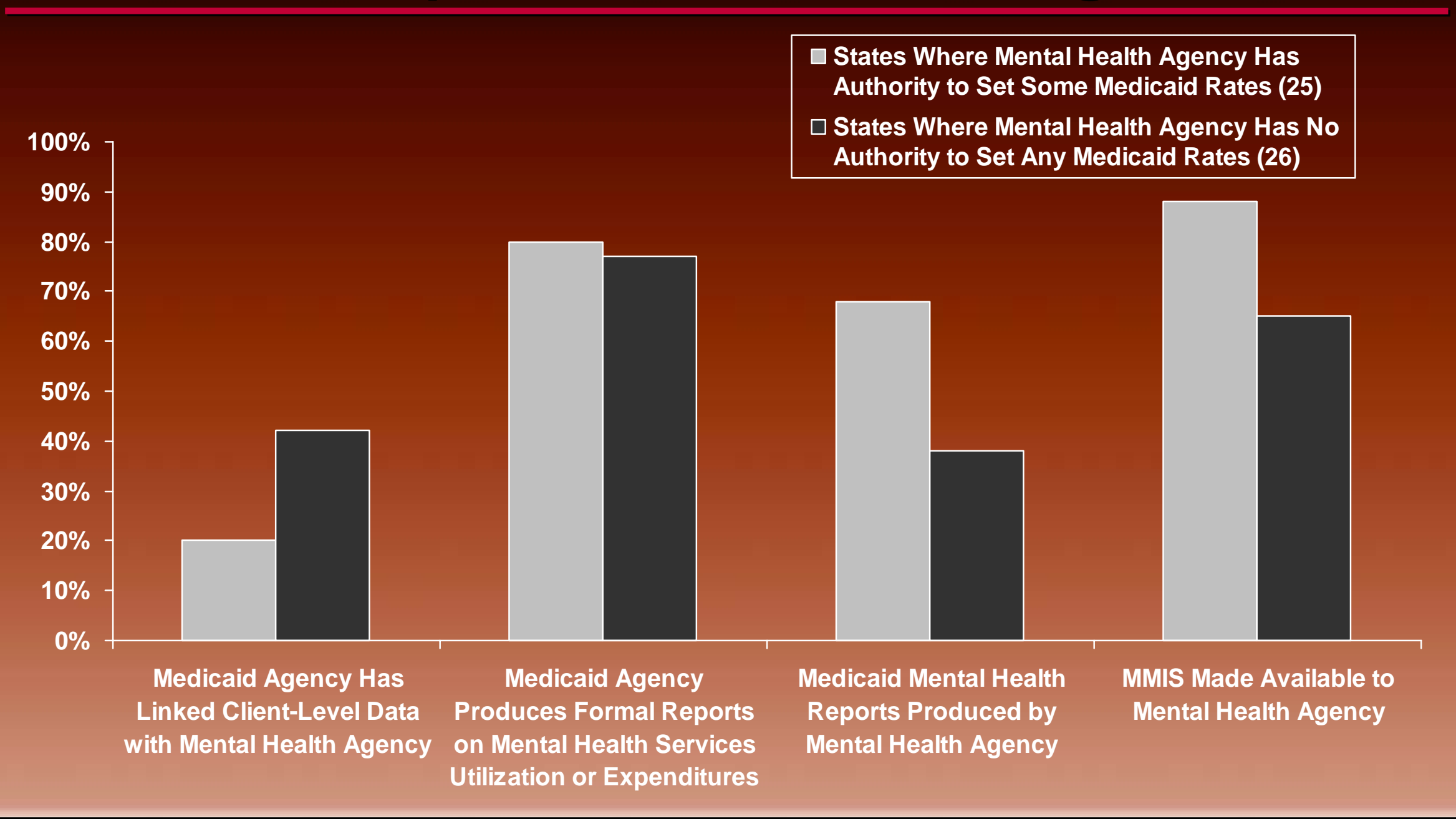




\section{Indicators of Stakeholder Involvement}

- At least one slot was reserved for a MH representative on the Medicaid Medical Care Advisory Committee (MCAC) in 32 states

- Consumer representative (12 states)

- Provider representative (22 states)

- Mental health agency representative (12 states)

- Other (6 states)

- Medjcaid MH policy working groups

- 47 states reported one or more such groups

- 46 states reported that representatives of community adjvocates and/or providers were represented

- Most common state agency representatives were from lyedicajd and lyju agencies 


\section{Four State Types}

- States with higher levels of Medicaid-MH collaboration (8 states)

- States with lower levels of Medicaid-MH collaboration (8 states)

- States with higher levels of Medicaid agency authority over Medicaid MH services (4 states)

- States with lower levels of Medjicajd agency authority (5 states)

- Two states fit into more than one category, and 28 states could not easily be categorized in this way 


\section{Characteristics of Higher Collaboration States}

- Measures used for classification

- Regular meetings between Medicaid and MH agency directors and agency staff

- Self-reported "frequent" collaboration

- One or more "very influential" joint workgroups

- Links between Medicaid and MH data

, Other features in common

- Agencies in same umbrella agency in 6 of 8 states

- ylj agency had no authority to set rates in any of the eight states

- Ejght states Were LA, IMA, NVV, NJI, NC, OK, PA, and WVJ 


\section{Characteristics of Lower Collaboration States}

- Measures used for classification

- Staff meetings quarterly or less often

- Self-reported "occasional" collaboration

- Medicaid agency does not participate in developing state MH plan

- Medicaid agency does not make MMIS data available

- No more than 1 higher collaboration measure reported

, Other features in common

- In same umbrella agency in only two of the states

- States generally lower in population

- 4 of the 8 states have fragmented authority for state IJ] system

- Eighit stajes were CO, DE, DC, fll, IJSS, IJIT, SD, and UT 


\section{Classification of Lower and Higher Medicaid Agency Authority States}

- Five measures of lower Medicaid agency authority, relative to $\mathrm{MH}$ agency

- Some funds for Medicaid MH services come from a source different from other Medicaid funds

- MH providers are paid differently from other providers

- MH providers are certified/enrolled in Medicaid differently from other providers

- MH agency has authority to set more than one rate or sets the capitation rate for mental health services

- At least some $1 \mathrm{y}$ H services or populations are carved out of regular Mledjcajol

- Lower MJedicajd authority states: CA, MJl, OH, OR, WA

- fligher IJeodicajd authority states: AR, ND, OK, SD 


\section{Other Features in Common}

- Lower Medicaid authority states

- In the same umbrella agency in $\mathbf{4}$ of the $\mathbf{5}$ states

- Larger populations

- High levels of reported collaboration

, Higher Medicaid authority states

- In the same umbrella agency in only two of the four states

- Reported fewer meetings and other indjcatiors of collaboration

- Smaller populations 


\section{Conclusions}

- Collaboration between Medicaid and MH agencies is important because of growing Medicaid role in financing $\mathrm{MH}$ services

- Medicaid needs to understand MH clinical issues, and $\mathrm{MH}$ needs to understand Medicaid fiscal and regulatory constraints

, Medicaid and MH working groups can help with common problems, such as:

- Behavioral health managed care

- Services for childolren with behavioral health problems

- Services for adulis with both mental and physical disabilities 


\section{Conclusions (Cont.)}

- County and local responsibility for MH services can be a key factor in Medicaid-MH agency relationships

- Proposed modifications in state-level authority or changes in funding for $\mathrm{MH}$ services must take local concerns into account

, State government reorganizations should give greater attention to Medicaid-MH agency relationships

- Most past reorganizations have been driven primarily by other concerns 


\section{References}

- Buck, J.A. (2003). "Medicaid, Health Care Financing Trends, and the Future of State-Based Public Mental Health Services." Psychiatric Services 54(7), 969-975.

- Frank, R.G. and Glied, S. (2006). "Changes in Mental Health Financing Since 1971: Implications for Policymakers and Patients." Health Affairs, Vol. 25, No. 3, 601-613.

- Mark, T.L., et al (2007). "National Expenditures for Mental Health Services and Substance Abuse Treatment, 1993-2003." SAMHSA Pub. No, 07/-4227.

- White, J. and Draper, D. (2004) "Review of the Liferature on Administration and Policy Development for Mledicaid Miental Health and Substance Abuse Services." Whathematica Policy Research. 